\title{
Dores e delícias da menopausa: o que 'a feminilidade' tem a ver com isso?
}

\section{O Complexo de Jocasta: feminilidade e sexualidade pelo prisma da menopausa.}

LAZNIK, Marie-Christine.

Rio de Janeiro: Companhia de Freud, 2003. 288 p.

"Uma mulher sem um homem é como um peixe sem bicicleta." (inscrição em imã comprado em um shopping do Rio)

Tinha oitenta e um anos de idade. Chamavase dona Cândida Raposo.

[...] Pois foi com dona Cândida Raposo que o desejo de prazer não passava.

Teve enfim a grande coragem de ir a um ginecologista. E perguntou-Ihe envergonhada, de cabeça baixa:

- Quando é que passa?

- Passa o quê, minha senhora?

- A coisa.

- Que coisa?

- A coisa, repetiu. O desejo de prazer, disse enfim.

- Minha senhora, lamento lhe dizer que não passa nunca.

- (...) E... e se eu me arranjasse sozinha? O senhor entende o que eu quero dizer?

- É, disse o médico. Pode ser um remédio.

[...] Nessa mesma noite deu um jeito e solitária satisfez-se. Mudos fogos de artifícios. Depois chorou. Tinha vergonha. Daí em diante usaria o mesmo processo. Sempre triste. É a vida, senhora Raposo, é a vida. Até a benção da morte.

A morte.

Pareceu-lhe ouvir ruído de passos. Os passos de seu marido Antenor Raposo.

(Clarice Lispector, A Via Crucis do Corpo)

O livro da psicanalista Marie-Christine Laznik O Complexo de Jocasta: feminilidade e sexualidade pelo prisma da menopausa (tradução de Sandra Regina Felgueiras e revisão da própria autora) é, sem dúvida, importante, na medida em que propicia uma reflexão sobre a menopausa, uma época que marca as mulheres de forma bastante específica, muitas vezes confundida com a velhice: "Esse deslizamento de cerca de trinta anos entre os cinqüenta e a idade avançada é habitual e, no entanto, aterrador" (p. 38). O livro discute questões interessantes, como o medo de envelhecer, o medo da perda da beleza e da juventude, a vivência da 'despersonalização', em que a mulher não reconhece sua própria imagem no espelho, a questão da divisão das mulheres entre a profissão e a relação afetiva, e O TRH (tratamento de reposição hormonal).

Outro aspecto de interesse do livro é que ele procura compreender por que grande parte das mulheres renuncia a viver sua sexualidade na menopausa, renúncia que a autora vê como estando relacionada ao "interdito de representação onipresente em nossa sociedade, o de pôr em cena os amores de uma mulher depois da menopausa" (p. 206). Porém, o livro não trata apenas das mulheres 'renunciantes', mas também das mulheres 'desejantes', 
chamadas "mulheres de coração de homem" já que a autora concorda com Freud que "a libido é só uma e é masculina" (p. 52) - com "traços de audácia e de agressividade", mulheres que foram filhas preferidas do pai e amantes de homens bem mais jovens, tais como as escritoras Collete e Simone de Beauvoir, e "mulheres que experimentam um amor por elas mesmas". Segundo a autora, essas mulheres "são protegidas do envelhecimento por seu narcisismo, verdadeiro elixir da juventude" (p. 115), "capazes de antecipar o futuro desastre de sua beleza, orientando-se para atividades mais masculinas, carreiras políticas ou outras, em que terão que tomar a palavra, num registro fálico" (p. 162).

O conceito de falo vai ser tomado como "um instrumento precioso para figurar a dissimetria necessária à economia do desejo do casal" ( $p$. 13), a chamada "disparidade fálica". Segundo Laznik,

o que permite o desejo de um homem perdurar não é o brilhantismo dos êxitos de sua companheira, ao contrário, nem mesmo o brilho de um corpo perfeito, mas exatamente sua falta. [...] O desejo dele só se mantém ao crer perceber nos olhos dela que é provido do que lhe falta (p. 12).

Apoiando-se nas fórmulas da sexuação de Lacan, ela vai explicar por que existe apenas a classe dos homens, inteiramente submetidos à questão fálica, e não é possível haver "a classe das detentoras da vagina" (p. 99). A tese central do livro é que a identidade feminina se encontra, para toda mulher, na "dependência radical com relação ao olhar apaixonado do Outro", que pertence à classe dos homens (p. 92). Segundo a autora, a "mulher é dividida entre seu ser de sujeito - que pode, no meio da vida, conhecer um enorme poder fálico - e sua feminilidade, sua capacidade de sedução na relação com o Outro, do outro sexo" (p. 93). Para Laznik, o fenômeno da despersonalização ocorre justamente porque na menopausa se 'retira' da mulher seus 'documentos de identidade', essenciais à sua capacidade de sedução na relação com o homem. A autora chega mesmo a se referir ao "passaporte" que representa ser jovem "e seus corolários, bela e esbelta" (p. 100). Outra perda importante na menopausa é a menstruação, vista como 'garantia' da identidade feminina e da maternidade.

O conceito de identidade é central no livro, aparecendo já na dedicatória da autora:

Em homenagem Àquele graças ao qual, dia após dia, encontro minha identidade feminina (p. 5).
Falar em identidade de mulher, no singular, fez sentido quando a teoria feminista estava começando a se desenvolver. Hoje, passados mais de 20 anos de pesquisa e, sobretudo, do crescimento dos movimentos das minorias, identidade se tornou uma questão política, de relações de poder, de delimitação de fronteiras que separam o eu e o outro. A própria idéia de identidade foi solapada pela questão da diferença, que denuncia a instabilidade do conceito. Se existe, sim, como mostra Teresa de Lauretis, a mulher no singular, como "um destilado de discursos dominantes diversos e congruentes das culturas ocidentais (discursos críticos e científicos, literários e jurídicos), que funcionam tanto como seu ponto de fuga quanto como sua condição específica de existência",' um dos projetos da teoria e da prática feministas é justamente entender como se dá a relação entre mulher e mulheres, seres históricos diversos, posicionados diferentemente no mundo. Se Laznik continua a falar hoje em identidade feminina e, principalmente, em 'garantia' de uma identidade, é justamente porque seu trabalho não inclui a diferença entre mulheres. Como ela coloca, o livro "se inscreve no tempo de emancipação das mulheres. Só fala daquelas que, no nível do social, obtiveram condições de vida bem mais igualitárias com relação a seu parceiro masculino. Para as mulheres ainda submetidas a uma verdadeira opressão, é fora de propósito" (p. 12). Ou seja, a 'identidade feminina' de que trata o livro se refere apenas às experiências de mulheres privilegiadas, que não são marcadas pela opressão. Isso significa que as outras não são mulheres? "Ain't I a woman?", já no século XIX perguntava Soujourner Truth, escrava americana, em seu discurso anti-escravagista. Em um artigo sobre "o humano numa paisagem póshumanista", Donna Haraway levanta a questão de

por que, 150 anos depois, sua pergunta tem mais força para a teoria feminista do que quaisquer frases afirmativas e declarativas? 0 que existe em relação a essa figura, cujo difícil nome significa alguém que jamais poderia ficar em casa, para quem a verdade era o deslocamento do lar, alguém que compele a recontar e reouvir sua história? Que tipo de história poderia habitar Sojourner Truth? Para mim, uma das respostas a esta pergunta está na força de Sojourner Truth para figurar uma humanidade coletiva sem construir o enclausuramento cósmico da categoria não marcada. Muito pelo contrário, seu corpo, nomes e discurso - suas formas, conteúdos e 
articulações - podem ser entendidos como contendo a promessa de um universo nunca marcado, uma linguagem comum que faz exigências irresistíveis em cada um/a de nós, coletiva e individualmente, precisamente por sua radical especificidade, em outras palavras, pelos deslocamentos e resistências à identidade não marcada exatamente como meio de reivindicar o status de "humano". ${ }^{2}$

O artigo de Haraway faz parte de uma coletânea organizada por Judith Butler e Joan Scott, cujo título aponta para um acontecimento importantíssimo em nossa discussão aqui Feminists Theorize the Political. ${ }^{3}$ Ao contrário de Laznik, as feministas teorizam o político, isto é, consideram as relações de poder ao tratar da categoria de identidade, que em si mesma significa exclusão das pessoas marcadas pela opressão, de modo a "construir o enclausuramento" da categoria não marcada, como coloca Haraway. Como mostra Judith Butler, em seu artigo nessa coletânea, "as categorias de identidade nunca são meramente descritivas, mas sempre normativas e, como tal, excludentes. ${ }^{4}$ O artigo de Scott na mesma coletânea ${ }^{5}$ propõe que tratar da identidade implica analisar 0 posicionamento dos sujeitos e mostrar que a diferença é constituída relacionalmente. Como ela argumenta,

precisamos dar conta dos processos históricos que, através do discurso, posicionam sujeitos e produzem suas experiências. Não são os indivíduos que têm experiência, mas os sujeitos é que são constituídos através da experiência. A experiência, de acordo com essa definição, torna-se a origem de nossa explicação, não a evidência autorizada (porque vista ou sentida) que fundamenta o conhecimento, mas sim aquilo que buscamos explicar, aquilo sobre o qual se produz conhecimento. Pensar a experiência dessa forma é historicizá-la, assim como as identidades que ela produz. ${ }^{6}$

Finalmente, em seu artigo na coletânea, Chantal Mouffe propõe uma "política democrática radical" para o feminismo, em que a emancipação só pode ser entendida como tal quando se estender a todas as mulheres e não apenas a algumas poucas privilegiadas. ${ }^{7}$ Seu argumento principal

é que, para as feministas comprometidas com um projeto político cuja aspiração seja lutar contra as formas de subordinação existentes em muitas relações sociais, e não só contra aquelas vinculadas ao gênero, uma interpretação que nos permite entender como é construído o sujeito através de diferentes discursos e posições de sujeito é certamente mais adequada que uma interpretação que reduza nossa identidade a uma posição singular, seja de classe, raça ou gênero. Este tipo de projeto democrático é também melhor servido por uma perspectiva que nos permita compreender a diversidade de maneiras em que são construídas as relações de poder e que nos ajude a revelar as formas de exclusão presentes em todas as pretensões de universalismo e nas asseverações de ter encontrado a verdadeira essência da racionalidade. ${ }^{8}$

À teorização de Laznik, no entanto, a única diferença que importa é a diferença sexual, como tratada pela psicanálise. Ela parece perceber que seu livro está na contracorrente da teoria e da prática feministas, pois adverte logo de saída que ele "não é 'politicamente correto"' (p. 12). As aspas se devem ao fato de ela estar usando a expressão com uma certa ironia, no sentido de criticar as feministas anglo-saxônicas. Sua oposição ao feminismo anglo-saxônico - ao qual às vezes ela se refere como feminismo tout court - perpassa todo o livro, beirando as raias da implicância. Sua referência é o feminismo francês, representado por Simone de Beauvoir e Françoise Héritier. Considera que o fato de Beauvoir ter "adotado a posição freudiana em seu debate sobre a feminilidade tem conseqüências sempre atuais sobre o movimento feminista francês, que, na sua maioria, não segue os movimentos feministas anglo-saxões em sua senha contra Freud, em particular, e contra os homens, em geral" (p. 68). Quanto a Héritier, Laznik considera que, embora ela "situe seu trabalho no campo de uma certa postura feminista, não é a das americanas. Longe de querer apagá-la, ela assume que a observação da diferença dos sexos está no fundamento de todo pensamento" (p. 145) .

Laznik usa uma passagem de Héritier em que ela afirma que "a diferença sexuada e o papel diferente dos sexos na reprodução" constituem "a trave última do pensamento, sobre a qual está fundada uma oposição conceitual essencial: a que opõe o idêntico ao diferente" (p. 145). Maria Luiza Heilborn, que, assim como Laznik, se posiciona como estruturalista, em um artigo recente sobre o conceito de gênero, usa uma passagem muito semelhante de Héritier, afirmando a "impossibilidade de negação da diferença entre os sexos", fundamentada na ordenação do pensamento "em função de um 
equilíbrio entre as propriedades do idêntico e do diferente". 9 Heilborn e Laznik usam essa passagem de Héritier para afirmar a hierarquia - necessária - em que homens se colocam em uma posição de superioridade em relação a mulheres, ou, como se expressa Heilborn, o masculino se situe "sempre na posição de englobante frente ao feminino". ${ }^{10}$ De acordo com sua postura estruturalista, essas duas autoras não vêem a dominação representada nessa posição privilegiada dos homens. Por outro lado, o fato de Héritier ocupar a cadeira de Lévi-Strauss no Collège de France não a impede de ver a dominação masculina, que ela localiza como estando assentada sobre a fecundidade. Para ela, portanto, o controle das mulheres da própria fecundidade possibilita-Ihes uma saída do lugar de dominação. Como Heilborn e Laznik afirmaram, Héritier realmente considera que a oposição entre idêntico/diferente é fundamental e impossível de ser evitada. Porém, ela dá abertura ao político, mostrando-se assim menos estruturalista que essas duas autoras, ao considerar que

esta diferença não implica como corolário obrigatório a desigualdade hierarquizada absoluta, nos termos que conhecemos. Esta é função da apropriação da fecundidade feminina. Se as mulheres reapropriarem o controle de sua fecundidade pela contracepção, elas mudam ipso facto as regras não apenas sociais mas também conceituais do jogo. [...] Agindo assim, elas acedem certamente à dignidade e à igualdade e, senão à inversão de todas as categorias hierárquicas das noções que governam nossos sistemas de representação, pelo menos a um equilíbrio melhor ou a uma nova repartição que faça com que o negativo não seja automaticamente associado ao pólo feminino nem o positivo ao pólo masculino. ${ }^{11}$

Em seu trabalho, Héritier também critica o ardor da pesquisa sobre Viagra em contraposição ao "domínio crucial e custoso da osteoporose que aparece com a menopausa" e termina nos alertando para mantermos a vigilância, pois "a preocupação dominante não é a igualdade dos sexos". ${ }^{12}$

Por outro lado, a questão da saúde na menopausa, à qual Héritier se refere, não é sequer mencionada no livro de Laznik, onde procriação e beleza ocupam todo o espaço, por serem estas associadas à 'identidade feminina' "tão duramente adquirida" e que ameaça se perder com a menopausa. Assim, os 'hábitos esportivos' de Diane de Poitiers, que cavalgava todos os dias, fazia exercícios ao ar livre, e cuidava da alimentação e do sono, são tidos como acontecendo apenas para "preservar a beleza" (p. 219) e não para sua própria satisfação pessoal e saúde, fundamentais para qualquer pessoa em qualquer idade. Essa preocupação com a aparência das mulheres vai colocar Laznik em defesa ferrenha do TRH, defesa esta que se mistura a seu incômodo/implicância com o feminismo anglo-saxônico.

As feministas americanas são, em geral, contra o tratamento de reposição hormonal, argüindo que os médicos querem, assim, manter as mulheres em lugar de objeto para 0 desejo dos homens. As francesas tendem a reivindicar o direito a esse tratamento, quer dizer, o direito de manter ainda durante certo tempo esse estado de mulher que nos tornamos depois de um tão longo percurso (p. 68-69). ${ }^{13}$

Chega a ser constrangedora essa tomada de posição em relação a um tratamento cujos resultados são ainda tão incertos e, certamente, relacionados ao lucro no mercado farmacêutico. Maria Coleta de Oliveira apresenta uma posição bem mais crítica em um artigo em que analisa o Congresso Internacional sobre a Menopausa, ocorrido em junho de 1993 em Estocolmo, onde

a ampla presença dos laboratórios farmacêuticos, não apenas nas dependências do Congresso, mas neste que constitui um campo privilegiado da pesquisa médica, fazia, por vezes, mesclar o cuidadoso discurso científico no relato de conclusões de pesquisa a proposições bem menos cautelosas acerca das maravilhas da reposição hormonal. Esta mescla torna por vezes muito difícil distinguir o que é um e o que é o outro, até porque algumas vezes o discurso é o mesmo.

Não há como eximir os médicos. Em primeiro lugar, a articulação entre os laboratórios e a corporação médica é orgânica. Muitos participam dos estudos pré-clínicos e clínicos dos laboratórios, muita pesquisa nos institutos, universidades e hospitais é financiada por companhias farmacêuticas. [...] Os laboratórios participam do programa científico dos congressos, tendo a possibilidade, em muitos casos, de organizar mesas-redondas, simpósios etc... As relações são, aparentemente de intimidade. ${ }^{14}$

Oliveira se preocupa com o fato de que muito poucos na comunidade médica se dêem conta de estarem participando no processo de construção da menopausa como um objeto e 
considera como sendo "assustador" nessa construção, em primeiro lugar, o fato de, "apesar do esforço verbal, o climatério [ser] visto como patológico, como uma etapa definida mais pelo negativo do que pelo positivo"15 e, em segundo lugar, o fato de o TRH ser apresentado como

uma pílula mágica, [que], tomada todos os dias, é capaz de afastar o fantasma do envelhecimento, alimentar a ilusão de juventude eterna. A pílula que, no dizer de um dos precursores da reposição hormonal, seria capaz de garantir às mulheres permanecerem "eternamente femininas". ${ }^{16}$

O discurso de Laznik reproduz o do precursor do TRH. Ela conclui seu livro falando de "nossa responsabilidade como mães" de ensinar a nossas filhas "o jogo do semblante, no qual se trata de jogar com a disparidade fálica" (p. 275), ou seja, ensinar às pobres moças como se mostrarem dependentes dos homens de modo a preservarem sua identidade de mulher, a todo custo. Isso também me parece assustador. Os dois textos escolhidos na epígrafe desta resenha se propõem a resistir a essa proposta, recorrendo ao cômico e ao trágico, no sentido que Ihes dá Nietzsche. $\mathrm{O}$ primeiro é uma inscrição em uma camiseta comprada em uma livraria feminista de Madison, Wisconsin, em 1983. No ano passado, encontrei, em um shopping do Rio, um imã com essa inscrição traduzida, e o coloquei no mural do meu escritório. Qual não foi minha alegria quando um dia minha afilhada, de 18 anos, achou engraçada a frase no imã e a copiou para mostrar às colegas. O conto de Clarice fala da masturbação, este recurso tão comum entre as mulheres, do qual pouco se fala e que é totalmente silenciado no livro de Laznik. A imagem engraçada do peixe pedalando uma bicicleta e a imagem - bela e triste - dos "mudos fogos de artifício" são minha proposta de oposição à imagem de um "Complexo de Jocasta", que mantém as mulheres prisioneiras do "familialismo" da psicanálise, tão bem discutido por Deleuze e Guattari em O AntiÉdipo. Considero essas duas imagens como um bom indicativo da possibilidade de um mundo em que a preocupação dominante seja a igualdade dos sexos, que só se torna possível quando se eliminam todas as formas de dominação.

' LAURETIS, Teresa de. Alice Doesn't: Feminism, Semiotics, Cinema. Bloomington: Indiana University Press, 1984. p. 5.
${ }^{2}$ HARAWAY, Donna. "O humano numa paisagem póshumanista". Trad. Marcos Santarrita. Revista Estudos Feministas, v. 1, n. 2, p. 277-292, 1993. p. 284-285.

${ }^{3}$ Em minha citação, usei a tradução do artigo de Haraway publicada na REF, v. 1, n. 2, 1993.

${ }^{4}$ BUTLER, Judith. "Contingent Foundations: Feminism and the Question of 'Postmodernism'. In: BUTLER, Judith, and SCOT, Joan. Feminists Theorize the Political. New York and London: Routledge, 1992. p. 3-21. p. 15-16. O artigo de Butler foi publicado em Cadernos Pagu, v. 1 1, 1998, com tradução de Pedro Maia Soares. A tradução da citação acima é minha.

${ }^{5}$ Traduzido na coletânea organizada por Alcione da Silva, Mara Lago e Tânia Ramos, Falas de gênero (llha de Santa Catarina: Editora Mulheres, 1999).

" SCOIT, Joan. "Experiência". In: Silva, Alcione L.; Lago, Mara C. S.; Ramos, Tânia R. O. Falas de gênero. Trad. Ana Cecília A. Lima. Ilha de Santa Catarina: Editora Mulheres, 1999. p. 21-55. p. 27.

7 Traduzido em Debate Feminista (México, São Paulo, 1999), edição especial sobre cidadania e feminismo.

${ }^{8}$ MOUFFE, Chantal. "Feminismo, cidadania e política democrática radical". Trad. Hortensia Moreno. Debate Feminista, São Paulo, México, p. 29-47, 1999. Edição especial: cidadania e feminismo. p. 47.

${ }^{9}$ HEILBORN, Maria Luiza. "Gênero: um olhar estruturalista". In: PEDRO, Joana Maria; GROSSI, Miriam Pillar. Masculino, feminino, plural. Florianópolis: Editora Mulheres, 1998. p. 43-53. p. 49.

${ }^{10}$ lbid., p. 52.

1 HÉRITIER, Françoise. "Vers un nouveau rapport des catégories du masculin et du féminin". In: HÉRITIER, Françoise; BAULIEU, Étienne-Émile; LERIDON, Henri. Contraception: contrainte ou liberté? Paris: Éditions Odile Jacob, 1999. p. 37-52. p. 48-49. Héritier esteve no encontro Fazendo Gênero IV, em maio de 2000, promovido pela REF e pela UFSC em Florianópolis. As citações aqui são do texto que ela usou em sua palestra e gentilmente nos emprestou para copiarmos. Tradução minha.

12 lbid., p. 52.

${ }^{13}$ Além de sua defesa do TRH, Lasnik considera também que, "no meio da vida, um trabalho psicanalítico pode evitar para uma mulher tornar-se renunciante e se deixar levar às diversas formas de depressão" (p. 175).

${ }^{14}$ OLIVEIRA, Maria Coleta de. "Às mulheres, os hormônios!" Revista Brasileira de Estudos Populacionais, Campinas, v. 9, n. 2, p. 184-188, 1994. p. 185-186.

15 lbid., p. 187.

${ }^{16}$ Ibid., p. 187.

Sandra Azerêdo Universidade Federal de Minas Gerais 